\title{
Economia de comunhão e aprendizagem: uma perspectiva epistêmica*
}

\author{
Beatriz Quiroz Villardi** \\ Sergio Proença Leitão*** \\ DeIse Marques $* * * *$
}

SuMÁrio: 1. O movimento dos focolares e a economia de comunhão; 2. Características do movimento e do projeto de EdC; 3. Paradigmas e pressupostos na teorização sobre a gestão de empresas; 4. Estudos socioconstrutivistas em aprendizagem organizacional; 5. Considerações finais e recomendações para futura pesquisa.

SUMMARY: 1 . The Focolare movement and the communion economy; 2 . Characteristics of the EoC movement and project; 3. Paradigms and assumptions of business administration theorization; 4 . Socio-constructivist studies on organizational learning; 5. Final remarks and recommendations for future research.

Palavras-Chave: economia de comunhão (EdC); movimento dos focolares; aprendizagem; mudança transformadora; perspectiva metaparadigmática; espiritualidade da unidade; amor cristão.

KEY WORDS: communion economy (EoC); Focolare movement; learning; transformational change; metaparadigmatic perspective; spirituality of unity; Christian love.

Este artigo compara e analisa epistemologias pertinentes para orientar a teorização sobre as práticas do projeto de economia de comunhão (EdC). Considera estudos acadêmicos já publicados no Brasil sobre aquele projeto empresarial e econômico de orientação espiritual cristã. Para isso também

\footnotetext{
* Artigo recebido em fev. e aceito em ago. 2007.

** Professora adjunta da Escola de Gestão e Negócios/Unigranrio. Endereço: Rua da Lapa, 86, 9o andar - Centro - CEP 20021-180, Rio de Janeiro, RJ, Brasil. E-mail: rbvillardi@hotmail.com. ***: Professor associado do IAG/PUC-Rio. Endereço: Rua Marquês de São Vicente, 225 — Gávea — CEP 22453-900, Rio de Janeiro, RJ, Brasil. E-mail: proenca@iag.puc-rio.br.

$* * * *$ Doutoranda do IAG/PUC-Rio. Endereço: Rua Marquês de São Vicente, 225 - Gávea CEP 22453-900, Rio de Janeiro, RJ, Brasil. E-mail: proenca@iag.puc-rio.br.
} 
considera a vocação de suas pequenas e médias empresas para a aprendizagem coletiva e examina os pressupostos subjacentes aos paradigmas de pesquisa em administração. Seu propósito é contribuir para a formulação de uma teoria sobre EdC.

Communion economy and learning: an epistemic view

This article compares and analyzes pertinent epistemologies to guide the theorization on the communion economy project (EoC) practices. It considers academic studies published in Brazil about that Christian-oriented entrepreneurial and economic project. It also takes into account the vocation of those small and medium enterprises for collective learning and examines the underlying assumptions of business administration research paradigms. Its purpose is to contribute for the formulation of an EoC theory.

Quando propus a economia de comunhão, com certeza não tinha em mente uma teoria. Vejo, entretanto, que ela chamou a atenção de economistas, sociólogos, filósofos e estudiosos de outras disciplinas, que encontram nessa experiência nova e nas idéias e categorias a ela subjacentes, motivos de interesse que vão além do movimento, no qual ela historicamente se desenvolveu.

Chiara Lubich

\section{O movimento dos focolares e a economia de comunhão}

Os desequilíbrios na concentração de renda entre países e entre classes sociais, principalmente nos países periféricos, permanecem como um dos grandes problemas da atualidade. Foi essa desigualdade que impulsionou a criação do projeto de economia de comunhão (EdC), concebido a partir do movimento dos focolares, por Chiara Lubich, sua fundadora e líder carismática. O projeto de EdC, versão empresarial e econômica do movimento, surgiu no Brasil em 1991, com a idéia de criar empresas dirigidas por pessoas éticas, honestas e competentes que se dispusessem, livremente, a partilhar parte dos lucros a serviço do bem comum.

Quando a italiana Chiara Lubich propôs o projeto de EdC, ela não pensou em uma construção teórica, mas em uma resposta concreta a uma necessidade real da sociedade. Mas, quando o projeto começou a se tornar realidade, ela convocou a comunidade acadêmica para estudá-lo (Lubich, 2002:13). Os primeiros a aceitarem tal apelo foram os estudantes de diversos países, principalmente da Itália. Em 2006 existiam 291 monografias, dissertações e teses, 
em diversas áreas de conhecimento, catalogadas no banco de dados do escritório central do projeto de EdC na Itália, segundo os dados do site www.tesi.ecodicom.net.

De fato, a comunidade acadêmica começa a manifestar interesse pela pesquisa nessa nova forma de economia solidária no sentido de partilha. $O$ domínio das monografias, dissertações e teses denuncia a presença maior da parte jovem da academia que começa a se interessar por essa nova experiência - formada principalmente por micro, pequenas e médias empresas - , para avaliá-la, no campo da administração, quanto a sua viabilidade e diferencial competitivo. Para Almeida e Leitão (2003), seu potencial transformador da vida e da forma de gestão é o fato gerador do crescente interesse da comunidade acadêmica por aquele projeto que associa gestão de empresa com espiritualidade cristã. Os textos básicos do movimento e do projeto são os evangelhos e a doutrina social da igreja.

Neste artigo discutem-se epistemologias pertinentes a um maior entendimento do fenômeno EdC como objeto de estudo e teorização. Especificamente, a natureza do conhecimento que orienta a prática dessas empresas, a partir da natureza do projeto de EdC e das tendências observadas nos textos que as estudam, associando-a à natureza dos conceitos teóricos usados em administração, particularmente sobre aprendizagem. Considera-se aqui a teorização como um processo socialmente construído pelos pesquisadores em interação com seu objeto de estudo. Avalia-se também a aprendizagem como um processo associado à prática dos empresários desse projeto, segundo indicado por Kurtz (2005) e Sampaio (2006).

Em seus 16 anos de existência, o projeto de EdC se apresenta, para a maioria dos pesquisadores que o estudam, como uma via alternativa para a completa instrumentalização da vida empresarial e da vida associada como um todo. Uma alternativa para o consumismo e o utilitarismo dominantes na lógica do mercado, potencialmente capaz de transformar a atual forma de gestão capitalista (Pinto e Leitão, 2006). Essas empresas estão mudando o paradigma dominante e a ideologia produtivista que lhe dá sustentação, ao se orientarem para uma forma de economia solidária, de partilha. Talvez o mais importante sobre elas seja estarem demonstrando quanto ao que pode ser feito, quando se tem vontade política para fazê-lo, diferenciando o que é factível da utopia, a partir de uma motivação de origem espiritual.

Com essa visão de mundo, essas empresas trazem em sua bagagem conceitual o germe da mudança. E isso parece ocorrer pela ênfase no caráter comunitário, na importância dada à qualidade das interações pessoais para construir relacionamentos e promover ajuda mútua. Com tal ênfase, o significado dado à atividade produtiva, individualmente, ultrapassa o simples objeti- 
vo de produzir bens e serviços gerando lucro, administrando poder e conhecimento, que é a outra natureza das organizações produtoras. A visão comunitária nessas empresas organiza a produção e a partilha do lucro.

A economia de comunhão, segundo Lima (1999), teve sua inspiração no movimento dos focolares, surgido na cidade de Trento, Itália, em 1943, em um porão de uma casa destruída pelos bombardeios da aviação aliada. A jovem Chiara Lubich e suas amigas, entre elas Ginetta Calliari, sensibilizadas pelos horrores da guerra e as necessidades urgentes dos habitantes da cidade, a quem procuravam atender, pensaram em um movimento capaz de reduzir a miséria e inibir a emergência de novas guerras. $\mathrm{O}$ grupo de jovens buscava viver segundo o modelo das primeiras comunidades cristãs, motivadas pelo amor ao próximo, com atenção imediata para os mais necessitados.

O movimento focolare (em italiano, fogo no lar, porque se reuniam em volta de fogueiras) surgiu com o objetivo de concretizar a fraternidade universal, por meio da prática da espiritualidade na unidade entre os povos. Busca fomentar o diálogo entre os diversos setores e religiões da sociedade humana. A construção dessa unidade (comunhão) deveria ter reflexos sobre o mundo econômico e do trabalho, da política e da justiça, da saúde, da cultura e da mídia (Lima, 1999).

Para materializar esse ideário o movimento começou por fundar pequenas comunidades - atualmente são 70 - em vários locais do mundo onde convivem pessoas de diversas nacionalidades e formações. No Brasil, de acordo com Lima (1999), a primeira das cinco "mariápolis", como se chamam essas cidadelas, foi instalada em Recife, em 1958.

A proposta de Chiara Lubich era montar empresas com pessoas éticas e competentes, dispostas a partilhar, com os mais necessitados, os resultados de seu trabalho (Calliari, 2000:20). Ou atrair pessoas com essas características, de empresas já existentes, insatisfeitas com o atual nível ético das práticas empresariais e com a crise socioambiental que castiga o planeta. O projeto de EdC tem hoje esses dois tipos de empresários.

O projeto fugiu a uma visão economicista de organização produtiva, sem aderir ao assistencialismo, porque preocupado com uma concepção humanista da atividade econômica (Sorgi, 1998:31). Rejeita a penetração do mercado em todas as dimensões da vida, mas o aceita como organizador das trocas, procurando um capitalismo menos concentrador e mais distributivo. $\mathrm{O}$ propósito do projeto EdC é ambicioso: mudar as empresas para mudar a economia e a sociedade como um todo.

Para reduzir as desigualdades, Chiara Lubich (2002:13), líder carismática do movimento e do projeto, queria empresas eficientes que gerassem lucros a serem partilhados: uma parte para os pobres, outra para o reinvestimento no 
próprio negócio e a terceira, para a formação de um "homem novo". E isso iria requerer pessoas imbuídas do espírito de comunhão e solidariedade, porque seriam precisos homens novos para formar uma sociedade nova. E também um longo caminho de aprendizado.

Essas organizações são definidas como "empresas de propriedade privada, em todos os sentidos, plenamente inseridas no mercado, que salvaguardam a propriedade particular dos bens, mas colocam o lucro - que a ideologia capitalista considera a finalidade da empresa —, em comunhão" (Bruni, 2005:25).

Em 2005, segundo o escritório do projeto no Brasil, em Vargem Grande Paulista, no interior de São Paulo, operavam 735 empresas espalhadas pelos cinco continentes, atuando em mais de 90 atividades produtivas e, desse total, 121 estavam no Brasil. A maior parte nos pólos, que operam como centros de trabalho de ajuda mútua. No Brasil, são cinco pólos, sendo o principal o de Vargem Grande Paulista. O crescimento anual líquido de empresas filiadas ao projeto de EdC no Brasil foi de 7\%, no período 1991-2005 e, no mundo, de 13\%. Em 2006 estimava-se o número de empresas em 830.

\section{Características do movimento e do projeto de EdC}

Lubich (2002:17) cita algumas características do projeto de EdC que considera significativas e identificam sua visão de mundo.

v Os sujeitos das empresas de EdC procuram seguir o mesmo estilo de comportamento que vivem nos outros âmbitos da vida.

$\checkmark$ Na EdC propõem-se comportamentos inspirados na gratuidade, na solidariedade e na atenção aos menos favorecidos, não apenas nas atividades sem fins lucrativos, mas também em empresas onde o lucro é um objetivo que, no entanto, deve ser colocado em comunhão.

v As empresas de EdC se apóiam e se desenvolvem em pólos industriais. As que estão geograficamente distantes se unem em torno do ideário do projeto por meio de congressos e periódicos onde compartilham suas práticas.

- Os indivíduos em dificuldades econômicas, destinatários dos lucros distribuídos, não são considerados assistidos ou beneficiários das empresas, mas membros ativos do projeto porque eles partilham a "cultura do dar", "dando" as suas necessidades.

v Na EdC a ênfase não está na filantropia, mas na partilha numa cultura do "ser", que se opõe à "cultura do ter" nos termos de Eric Fromm, psicanalista da Escola de Frankfurt. 
O movimento dos focolares expandiu-se ao longo dos anos e hoje conta, entre aderentes e simpatizantes, com cerca de 8,5 milhões de pessoas espalhadas pelos cinco continentes.

Linard (2003) caracteriza o movimento focolare e as práticas de gestão nas empresas do projeto de EdC, apontando fatores culturais e organizacionais sistêmicos, que explicam sua disseminação, da forma a seguir.

1. Fatores sistêmicos relativos ao próprio movimento focolare.

- Filosóficos e ideológicos: crença profunda na unidade da família humana sem distinção de raça, nacionalidade ou credo religioso concretizada por uma nova ética social (cultura da partilha).

- Práxis: 60 anos de experiência de uma comunhão de bens e de formação do "homem novo".

v Autoridade moral: uma líder carismática, a fundadora Chiara Lubich, que, em idade avançada, continua priorizando a economia de comunhão e obteve endosso do papa João Paulo II, da academia que lhe concedeu títulos de doutor honorário e de esferas políticas dos partidos de esquerda e de direita na comunidade européia e latino-americana.

- Estrutura organizacional: conectada por fortes relações pessoais e comunicação regular com a líder, porém com estruturas celulares descentralizadas localmente.

- Infra-estrutura: uma rede de formação e educação do homem novo em níveis local e internacional, uma rede de comunicação global mensal onde reportam por 40 minutos os avanços locais e internacionais; editoras próprias, websites (e listas de discussão) em várias línguas, centros de formação e treinamento, mariápolis, conferências e seminários regulares para compartilhar as experiências locais.

2. Fatores sistêmicos relativos às empresas participantes do projeto EdC, seus empresários, empregados e beneficiários da distribuição dos lucros.

v Diversidade e independência dos empreendimentos permitindo-se diversas formas de gestão, de organização e de atividades produtivas.

- Canais de comunicação diversos para troca de idéias entre os respectivos stakeholders dos diversos empreendimentos.

- Idealismo fundamentado na apropriação explícita de capital nas empresas destinado à expansão e criação de empregos.

v Ética que promove elevada qualidade do quadro de gestão e dos serviços aos clientes. 
\ Propósito de desenvolver relações e cooperar com outros negócios inclusive com os concorrentes.

Há indícios de que tais práticas possibilitam a mudança transformadora por meio da aprendizagem coletiva de seus membros (Kurtz, 2005; Sampaio, 2006). E que introduzem uma reconceitualização do presente capitalismo predatório, para transformá-lo, resgatando o sentido das organizações e do trabalho de modo sustentável (Pinto e Leitão, 2006:32).

Seis indícios foram apontados na produção acadêmica no Brasil sobre a forma de gestão nas empresas da EdC.

1. A caracterização feita por Kurtz (2004) e confirmada por Sampaio (2006), em seus estudos sobre aprendizagem nessas empresas, quanto a:

v seus fundamentos ontológicos: amor $^{1}$ e comunhão;

v uma filosofia da empresa onde se valoriza os funcionários, onde existe acesso às informações e preocupação com as formas de remuneração e autonomia,

v um clima organizacional de família, contentamento, segurança e bom humor onde a aprendizagem se dá naturalmente na ação e em equipe, por um modo de relacionamento estimulado pelos empresários da EdC, particularmente naqueles pertencentes ao movimento dos focolares (Sampaio e Leitão, 2007).

2. Modos e qualidade dos relacionamentos interpessoais e interorganizacionais marcados pela solidariedade, diálogo, liberdade, igualdade, compreensão, confiança, respeito, responsabilidade, honestidade e sinceridade, conforme detectado por Pinto (2004).

3. A prática de uma espiritualidade na unidade (comunhão), informada por Lima (1999), por Gonçalves (2005) e por Machado (2006) e do amor cristão em oposição ao materialismo e instrumentalidade que pautam a lógica de gestão predominante e é elemento central da cultura da partilha.

4. A prática da partilha dos lucros entre os menos favorecidos com um entendimento de que todos participam em comunhão, seja com entrega dos resultados do trabalho conjunto, seja com entrega de suas necessidades como relatado no caso Femaq por Gonçalves e Leitão (2001) e também por Kurtz (2005).

\footnotetext{
${ }^{1}$ Amor tem aqui o sentido da palavra grega agape usada por Cristo, que significa amor-comportamento manifesto na aceitação do outro como ser legítimo na convivência independentemente de se gostar dele ou não. Difere, portanto, de amor-sentimento.
} 
5. A ênfase na busca da justiça social considerada a práxis da espiritualidade. Essa práxis, proposta pela sua líder Chiara Lubich, deve desenvolver uma cultura da partilha pelo exemplo pessoal, nas empresas filiadas ao projeto EdC (Lubich, 2004; Machado, 2006).

6. A racionalidade substantiva condutora da atuação dos gestores do projeto EdC e a existência de um grande potencial para transformar organizações econômicas de orientação dominantemente instrumental em organizações substantivas, apontado por Almeida (2002).

Esses seis indícios apontam diferenças conceituais e axiológicas com o predominante estrutural-funcionalismo e suas teorias organizacionais (Machado, 2006). Sugerem uma cosmovisão e pressupostos diferentes sobre a natureza humana e a mudança, algo próximo daqueles que fundamentam o comportamento das organizações de aprendizagem (OA), principalmente nos termos de Senge (1990), com sua influência zen-budista, ou da visão de Hawkins (1991) quando fala de aprendizagem de nível III (substantivo).

O estudo de Kurtz (2005) deixou evidências de que a qualidade dos relacionamentos interpessoais na empresa de EdC estudada, favorecia a aprendizagem de tarefas e comportamentos. O estudo de Sampaio (2006) mostrou fortes similaridades entre a ambiência das quatro empresas estudadas com 14 características comuns à concepção de organização de aprendizagem (OA) levantadas por Carvalho (1998) em seu estudo teórico. Os dois estudos empíricos acima mencionados vinculam EdC à aprendizagem e mudança: mudança da organização na adoção de uma cultura da partilha, como nas suas estratégias de mercado. Indicam, portanto, um claro vínculo entre o conhecimento inerente à maneira $\mathrm{EdC}$ de ser, a aprendizagem e a mudança transformadora nas organizações daquele projeto.

Tais indícios aproximam essas empresas das propostas do humanismo radical, como caracterizado por Burrel e Morgan (1979) e identificado empiricamente por Aktouf (1996), quando estudou as empresas do grupo espanhol Mondragón e do canadense Cascades. Como também permite perceber vínculos com o interpretativismo, em face de sua forte vinculação com o simbolismo do humanismo cristão orientador do projeto de EdC.

\section{Paradigmas e pressupostos na teorização sobre a gestão de empresas}

A natureza transcendente do papel da organização econômica na economia de comunhão traz de volta a discussão sobre nossos pressupostos de conhecimento e sobre a subjetividade. Como também seu forte simbolismo e o significado 
inerente a uma práxis cristã remetem a uma breve revisão sobre o papel dos paradigmas na pesquisa e na teorização sobre gestão. Remetem a Burrel e Morgan (1979) que examinaram e classificaram os pressupostos dos estudos sociais até os anos 1970, configurando-os em paradigmas de acordo com a epistemologia de sua construção e o tipo da mudança que admitem.

Ali eles apontam que o realismo, ontologicamente vinculado ao positivismo, rejeita o subjetivismo como integrante da realidade e da pesquisa. Já o nominalismo antipositivista admite a subjetividade envolvida no processo de produção de conhecimento e reconhece o pluralismo epistemológico. Nele, a realidade a ser estudada é produto da consciência do indivíduo e a subjetividade é integrante do conhecimento do pesquisador.

No subjetivismo a pessoa pode ver a verdade incluindo a si mesma (interpretativismo e humanismo radical), enquanto no objetivismo ela só a descobrirá fora de si (funcionalismo e estruturalismo radical). O subjetivismo vê o ser humano como gerador de processos sociais por meio de relações intersubjetivas, ideológicas e socioculturais, estabelecidas de modo voluntarista (não-determinista), pois se considera capaz de construir (e ser construído) nas suas relações interpessoais e ambientais. No projeto de EdC o subjetivismo penetra o transcendente, ante a forte presença de princípios espirituais.

Mas os dados que constituem o conhecimento são também determinados pela influência dos próprios paradigmas e valores dos pesquisadores, definidos por influência das tradições científicas nas quais foram educados e treinados, tanto quanto pela realidade por eles percebida (Astley, 1984). Na pesquisa sobre EdC, contudo, tais formas de ver requerem um confronto com os valores espirituais que orientam a gestão de suas empresas e a aceitação da intuição, valorizada naquele projeto, mas que não pertence à tradição científica.

É possível reconhecer que o corpo de conhecimento constitutivo das ciências que formam a administração é um produto socialmente construído, pois as observações empíricas são inevitavelmente mediadas por preconcepções teóricas moldadas pela cosmovisão com a qual os pesquisadores percebem os dados (Astley, 1984, 1985).

Destarte, pesquisadores que acreditam estarem engajados somente na atividade de ajudar os gerentes na maneira funcionalista de ver desconsideram o que é simbólico nas ciências humano-sociais. Talvez por não conceberem o "mundo da prática gerencial como uma rede de significados subjetivos onde os gerentes precisam interpretar a significância de suas próprias ações assim como a dos outros, e atribuir-lhes significado e sentido" (Astley, 1984:269). Da mesma forma, acrescente-se, tal visão funcional seja incapaz, por não estar interessada de explicitar os mecanismos de dominação existente, como também a intenção (política) de empresários de EdC de proceder com suas práti- 
cas de gestão a uma reforma social. Esse autor ressalta que as perspectivas teóricas fornecem aos decisores um conjunto flexível de ferramentas simbólicas, entre as quais o decisor também escolhe a que mais se aproxime de sua própria cosmovisão e ideologia.

Isso coloca a seguinte questão: se o conhecimento que se procura desenvolver sobre um fenômeno (aprendizagem, EdC) é compatível com os pressupostos do conhecimento que fundamentam a sua própria natureza, para se obter razoável aproximação dele, como aceita o antipositivismo. E lembra que o estudo compreensivo de um fenômeno requer que os pressupostos epistemológicos e metodológicos sejam ontologicamente compatíveis de modo a acompanhar a sua lógica e essência. De outro modo, aspectos expressivos desse fenômeno podem ser desconsiderados, perdendo-se riqueza, detalhamento e compreensão do mesmo.

\section{Paradigmas sociais}

Paradigmas, segundo Gióia e Pitre (1990), são conjuntos de pressupostos sobre a natureza dos fenômenos organizacionais (ontologia), sobre a natureza do conhecimento desses fenômenos (epistemologia) e sobre a natureza das formas de estudá-los (metodologia). Pressupostos são crenças e "certezas" que orientam as ações, automatizando-as, e por isso moldam a forma do ser humano ver o mundo configurando paradigmas.

Numa perspectiva multiparadigmática para a construção de teorias, Gióia e Pitre (1990) concordam com Burrel e Morgan (1979), que tem havido dominância do funcionalismo na teoria e pesquisa organizacional. E isso se aplica à grande maioria dos estudos sobre gestão do conhecimento, aprendizagem e mudança, mas não é claro quanto aos estudos já realizados sobre EdC. O olhar funcionalista está presente, mas não é tão dominante, pois convive com os pressupostos do interpretativismo e até mesmo com um caso único de olhar marxista, dentro de uma visão estruturalista radical (Wellen, 2004).

As críticas à teoria organizacional tradicional, fundada no funcionalismo, tinham sido apontadas também por Burrel e Morgan (1979), que as analisaram e compararam para formar a base de uma teoria antiorganização. O funcionalismo é por eles tratado como uma teoria da organização e o humanismo radical como uma teoria antiorganização. O paradigma sociológico ali denominado humanismo radical e sua correspondente teoria antiorganização tem pressupostos que pode explicar as práticas de EdC como uma visão que busca um aprender para mudar, transformando essas empresas no que se refere à lógica acumulativa do mercado. Isso porque ele possui características 
muito próximas às preocupações centrais do projeto de EdC, como por exemplo: considerar a humanidade como fonte de problema, em vez da ciência; buscar uma ontologia da consciência, preocupação com a cooperação e a convivência e não tanto com a competição; aceitação da intuição como cognição dominante; resgate da razão substantiva. Ou ainda outras preocupações características desse paradigma como o desenvolvimento de uma nova realidade ético-política.

As diferenças entre o funcionalismo, o humanismo radical e o interpretativismo foram apontadas por Gióia e Pitre (1990), segundo quatro aspectos das teorias elaboradas pelos pesquisadores desses paradigmas.

v Quanto às metas teóricas: o funcionalismo busca regularidades e testar para predizer e controlar a realidade. O humanismo radical busca descrever e criticar para mudar a realidade que investiga e alcançar liberdade pela revisão da consciência. E o interpretativismo procura descrever e explicar para diagnosticar e entender.

v Quanto à preocupação teórica: o funcionalismo foca a causalidade e a generalização. O humanismo radical, a construção social da realidade e em apontar as distorções e os interesses envolvidos. O interpretativismo está voltado para os processos de construção social da realidade, o processo de reificação e sua interpretação.

v Quanto à abordagem teórica: o funcionalismo pretende refinamento dos dados por meio de análise causal. O humanismo radical, pela revelação por meio de análise crítica, e o interpretativismo pela descoberta por meio de análise codificada dos dados.

v Quanto à construção teórica: o funcionalismo constrói teorias pelos resultados, mostra como a teoria é confirmada ou não, assim como o significado para os teóricos e para os profissionais. O humanismo radical as constrói pela análise dialética, mostrando como os níveis de consciência podem mudar, e o interpretativismo pela teoria substantiva, mostrando como o todo se arruma junto nos fenômenos que estuda.

Também em Alvesson e Deetz (1999:237) encontramos distinções entre esses três paradigmas. O quadro que ilustra este artigo estabelece comparações entre a visão normativa do funcionalismo, a visão construtiva do interpretativismo e o sentido crítico do humanismo radical no que se refere às características prototípicas de seus discursos no estudo das organizações. À exceção do caso do "Estado", na metáfora organizacional para o humanismo, e da "Suspeita", no Clima os demais tópicos comparativos do discurso crítico se 
ajustam em maior ou menor grau ao perfil do projeto de EdC traçado anteriormente. A aproximação com o interpretativismo é ainda mais evidente. Mas, para o discurso normativo, a distância é bem maior. O discurso dialógico pósmoderno não foi aqui considerado, por falta de semelhanças significativas com EdC. Também não há abordagens desse tipo já publicadas sobre o projeto, que vem sendo tratado como modernista pela maioria dos pesquisadores.

\begin{tabular}{|c|c|c|c|}
\hline \multicolumn{4}{|c|}{ Algumas características prototípicas do discurso } \\
\hline \multirow{2}{*}{ Tópico } & \multicolumn{3}{|c|}{ Visão } \\
\hline & Normativa & Construtiva & Crítica \\
\hline Objetivo básico & $\begin{array}{l}\text { Lei como relação entre } \\
\text { objetos }\end{array}$ & Exibir uma cultura unificada & $\begin{array}{l}\text { Desmascarar a } \\
\text { dominação }\end{array}$ \\
\hline Esperança & $\begin{array}{l}\text { Emancipação } \\
\text { progressiva }\end{array}$ & $\begin{array}{l}\text { Recuperação de valores } \\
\text { integrativos }\end{array}$ & $\begin{array}{l}\text { Reforma da ordem } \\
\text { social }\end{array}$ \\
\hline $\begin{array}{l}\text { Metáfora } \\
\text { organizacional }\end{array}$ & Mercado & Comunidade & Estado \\
\hline $\begin{array}{l}\text { Problemas a que } \\
\text { se dirigem }\end{array}$ & $\begin{array}{l}\text { Ineficiência e } \\
\text { desordem }\end{array}$ & $\begin{array}{l}\text { Falta de significado e de } \\
\text { legitimidade }\end{array}$ & $\begin{array}{l}\text { Dominação, } \\
\text { consentimento }\end{array}$ \\
\hline $\begin{array}{l}\text { Benefícios } \\
\text { organizacionais }\end{array}$ & $\begin{array}{l}\text { Controle, } \\
\text { especialização }\end{array}$ & $\begin{array}{l}\text { Comprometimento, qualidade } \\
\text { de vida no trabalho }\end{array}$ & $\begin{array}{l}\text { Participação, expansão } \\
\text { do conhecimento }\end{array}$ \\
\hline Clima & Otimista & Amigável & Suspeita \\
\hline Temor social & Desordem & Despersonalização & Autoridade \\
\hline
\end{tabular}

O interpretativismo, com suas raízes na tradição idealista alemã, assume que a realidade final do universo está no espírito, na idéia e não no que provém dos sentidos, como aceita o funcionalismo. O humanismo radical tem suas origens na mesma tradição e também declara que o homem constrói o mundo em que vive, mas com uma perspectiva crítica, para propor transformações, enquanto o interpretativismo se detém na pura compreensão do processo. É devido aos pressupostos subjetivistas compartilhados entre esses dois paradigmas que existe uma conexão direta entre o conceito interpretativista de estruturação e o conceito humanista de estrutura profunda. A diferença é que os humanistas agem sobre essas estruturas, apontando distorções e conscientizando os indivíduos a elas relacionados, enquanto os interpretativistas contentam-se em conhecer as regras desses processos de estruturação (Gióia e Pitre, 1990). 
Embora o interpretativismo e o funcionalismo tenham em comum a sociologia da ordem, a preocupação do interpretativismo em conhecer como a realidade social é construída possibilita o lançamento de uma ponte para a crítica humanista, considerada viável na perspectiva multiparadigmática de Gióia e Pitre (1999). Além disso, o interpretativismo aceita não só a idéia de um significado implícito em todas as ações humanas, como também adota um compromisso ético de vida, admitindo a contribuição da subjetividade criadora de significados, sem eliminar a busca da objetividade do conhecimento (Schwandt, 1994:189).

A visão interpretativista permite perceber que as relações simbólicas são tão importantes quanto às relações de produção e que a vida organizacional também precisa ser examinada nessa dimensão. Pessoas são mão-de-obra no processo produtivo, mas também são criadores de significados, pois o corpo e o simbólico, imanente de seu psiquismo, se complementam. E esse é um aspecto implícito, por vezes explícito, em todo o discurso de empresários do projeto de EdC, particularmente nos pertencentes ao movimento dos focolares.

No caso da economia de comunhão, o interpretativismo pode decodificar os valores da mudança implícita na mensagem humanista cristã disseminada pelos empresários do projeto. Essa mensagem não rompe, em toda a extensão, com o capitalismo; não rejeita as leis da oferta e da procura, mas relativiza o poder do individualismo e da competição, subordinando-os ao coletivismo e à cooperação. Restringe os limites da visão mercantilista ao âmbito das trocas de bens e serviços, retirando-a dos outros aspectos da vida coletiva. Volta-se contra uma política cognitiva centrada no mercado, no dizer de Guerreiro Ramos (1981:86), ao retirá-la das outras dimensões envolvidas nos relacionamentos interpessoais. É nesse sentido que a EdC constitui uma mudança transformadora.

A espiritualidade da unidade opõe-se ao individualismo. E o amor-comportamento (amor cristão) considera as usuais práticas competitivas como forma de rejeição do outro, sentido que também é dado pela biologia cognitiva de Maturana (2001:67), quando considera o amor como forma comportamental (domínio de ações) de aceitação do outro como um ser legítimo na convivência. A visão de Maturana mostra similaridade entre o conceito biológico de amor (aceitação do outro), princípio permissivo da vida coletiva, e o conceito cristão de amor-comportamento, que também é a forma básica de organização da vida social.

No âmbito do simbólico, por outro lado, podem estar fontes importantes da mudança perseguida pela perspectiva humanista radical, que vem denunciando as origens da alienação no trabalho (âmbito do simbólico) e os processos de dominação que afetam o corpo e o psiquismo do trabalhador. Existe aí um 
ponto de encontro e as duas perspectivas que, combinadas em uma visão metaparadigmática, podem contribuir sensivelmente para a compreensão do fenômeno EdC. Alguns pesquisadores, utilizando abordagens interpretativistas, deixaram indícios desse ponto de encontro em seus trabalhos (Pinto, 2004; Gonçalves, 2005; Machado, 2006).

Gióia e Pitre (1990), lembremos, não consideram a transição regulaçãomudança como uma zona particularmente densa, vendo relativa permeabilidade através dela. Acrescentando-se aqui que uma visão de múltiplas perspectivas relevantes é necessária para a compreensão e explicação de fenômenos humano-sociais, naturalmente complexos, para serem olhados apenas por uma única perspectiva.

Seguindo essa breve revisão de epistemologias vinculadas à teoria organizacional, cabe lembrar ainda que seus estudos foram classificados por Astley e Van de Ven (1983), resultando em quatro perspectivas organizacionais de acordo com os pressupostos sobre a natureza humana e os níveis de estudo abordados na teoria organizacional. São elas a perspectiva de seleção natural, a de ação coletiva, a estrutural-sistêmica e a da escolha estratégica.

Vale observar, particularmente, a perspectiva da ação coletiva, por suas aproximações com a maneira EdC de ser e suas práticas de aprendizagem coletiva. Do ponto de vista da estrutura organizacional essa perspectiva se vincula a comunidades ou redes de grupos semi-autônomos que interagem para modificar ou construir seu ambiente. São organizações que expandem a ação individual. Do ponto de vista da mudança, tal perspectiva aceita a barganha coletiva, a negociação e o compromisso, por meio de ajustamento participativo. O comportamento dessa organização é racional, coletivamente construído e com a ordem politicamente negociada e sua gerência é do tipo interativo e negociadora. A única e significativa diferença entre essa perspectiva e a do projeto de EdC é que, tal como apontado por Gonçalves e Leitão (2001) e Gonçalves (2005), os gerentes de EdC aceitam a intuição, como norteadora da razão, bem como usam a concepção cristã de providência divina, como algo capaz de intervir nos momentos mais críticos da gestão dos seus negócios. $\mathrm{O}$ subjetivo alcança o transcendente.

Sob a perspectiva da ação coletiva, podem-se entender as práticas da EdC correspondentes à perspectiva voluntarista da natureza humana, como capazes de realizar mudanças transformadoras pela aprendizagem (ou double loop learning, nos conhecidos termos de Chris Argyris), onde predominam os aspectos sociais no entendimento da realidade organizacional, em vez de apenas aspectos técnicos e econômicos.

Esse debate entre as perspectivas organizacionais proposto por Astley e Van de Ven (1983) trouxe à tona: diferentes pressupostos quanto a sua abran- 
gência explicativa e quanto à mudança que admitem; o entendimento de uma organização, como parte do mundo social, e em permanente estado de vir-a-ser; e o entendimento da complementaridade das teorias organizacionais existentes.

Assim, esses autores, ao considerarem a totalidade do fenômeno organizacional, perceberam que, por um lado, organizações são vistas como indissociáveis do contexto da sociedade na qual elas estão localizadas, como partes constituintes de padrões e forças mais amplas que se desdobram na sociedade em geral. Da mesma forma podemos dizer que a aprendizagem é parte indissociável do contexto organizacional (Callahan e Schwandt, 1999; MamedeNeves, 1999). Por outro lado, organizações também são capazes de ações parciais em seu próprio proveito. Essa tensão entre as partes e o todo foi captada pela análise do intercâmbio entre os níveis micro e macro examinados por Astley e Van de Ven (1983). E é percebida por muitos empresários e estudiosos de EdC que não separam organização de sociedade e de ambiente (Sampaio, 2006). Bem como conduzem a uma forma de aprendizagem que perpassa o conjunto das empresas que integram o projeto. Em EdC, o aprender é formalmente coletivo.

\section{Pressupostos organizacionais e individuais}

Em suma, os pressupostos organizacionais e individuais que integram os paradigmas permitem entender a orientação do trabalho do pesquisador e sua escolha de metodologias, assim como a orientação da ação dos gerentes nas organizações. Pressupostos individuais são convicções ou certezas internas, freqüentemente inconscientes, porém simplificadores necessários e inevitáveis no facilitar e automatizar os atos dos indivíduos.

A explicitação da influência mútua entre os pressupostos individuais e organizacionais resultou de um estudo sobre a identificação das práticas de desenvolvimento gerencial, de sete gestores, em seis empresas, feito por Villardi (1997). Detectou-se ali uma predominância voluntarista dos gestores que decidiram conscientemente utilizar técnicas não-tradicionais para desenvolvimento gerencial, com o propósito de propiciar desenvolvimento humano para além da pura técnica gerencial.

O propósito daquele grupo de gestores, segundo Villardi (1997), era orientado pela crença de que "se ajudou a mim, pode ajudar meus colegas", isto é, a prática dos gestores voluntaristas era orientada por uma experiência pessoal vivida diferentemente dos outros gestores estudados. Nesse estudo identificaram-se ainda processos de formação de pressupostos individuais ao longo da história pessoal daqueles gestores em que muitas de suas "verdades 
pessoais" foram se acumulando, não apenas baseados em sua experiência individual, mas também por meio de condicionamentos familiares e culturais.

Em tal processo, componentes emocionais foram se sobrepondo a outros de natureza racional e experimental; estruturaram-se e ocultaram-se no inconsciente tornando-se pressupostos mais complexos, até formarem uma intrincada teia indissociável da própria personalidade, originando e condicionando também grande parte das atitudes e valores desses gestores. No entanto, a existência desses pressupostos, embora acessíveis pela reflexão, era esquecida e ignorada conscientemente pelos gestores estudados, o que os levava a supor que seus atos e pensamentos derivavam predominantemente de uma lógica isenta e de dados objetivos, sem influências subjetivas formadas $a$ priori (Villardi, 1997).

Abordagens desse tipo não aparecem nos estudos atuais sobre EdC, embora possam contribuir para o entendimento da formação de pressupostos vigentes na economia de comunhão.

\section{Representativismo e construtivismo}

Representativismo e construtivismo são epistemologias que correspondem, nos termos de Burrel e Morgan (1979), a visões distintas da natureza humana, uma determinista e outra voluntarista respectivamente. O representativismo, historicamente a epistemologia predominante na pesquisa em administração, orienta uma ação instrumental, e um tipo particular de organização, a organização burocrática (Tsoukas, 1998). O representativismo acredita que o conhecimento desenvolvido (como uma teoria, por exemplo) reflete a realidade e o mundo "como é". No construtivismo, as teorias são consideradas ferramentas para agir no mundo mais que "espelhos" para refleti-lo (Tsoukas, 1998).

No representativismo, o pesquisador considera-se intérprete em busca de neutralidade e isenção sem expectativa de mudança nos pressupostos de ação. Enquanto, segundo o construtivismo, o pesquisador, e as teorias que produz, é considerado responsável por mudar a realidade, portanto deve questionar os pressupostos que a fundamentam e propiciar formas de ação ontologicamente diferentes das predominantes.

Assim, considerando a epistemologia realista (representativista) e a construtivista (anti-representativista) para desenvolvimento do conhecimento, Romm (2002:461) afirma como seu pressuposto que "as formas de definir os processos de conhecimento não podem ser separadas da maneira como operamos nossas interconexões sociais no esforço de tornar-nos responsáveis". Uma pesquisa sistêmica crítica é "aquela [pesquisa] onde a conexão sistêmica 
entre conhecer e agir é ressaltada e mantida conscientemente" (Romm, 2002:455).

Desse modo, diferentemente do representativismo, o construtivismo crítico reconhece a responsabilidade do pesquisador na construção de conhecimento e que ele deve estar relacionado à ação sobre a realidade num processo de construção e reconstrução. É algo afinado com as experiências dos empresários que, segundo apontado por Gonçalves (2005), estão aprendendo a mudar o paradigma dominante no mundo dos negócios, como é o caso das empresas de EdC. Algo que orientou essa pesquisadora em sua tese de doutoramento sobre EdC.

Construir (ou reconstruir) empresas para mudar práticas de mercado consideradas desumanizantes é objeto central da aprendizagem dos empresários de EdC. Essa prática deve ser incorporada à teorização, embora, em diversos estudos sobre o projeto, os pesquisadores procurem, de forma pretensamente neutra, espelhar o observado.

\section{Estudos socioconstrutivistas em aprendizagem organizacional}

Duas epistemologias do conhecimento desenvolvido sobre teorias organizacionais, particularmente sobre aprendizagem e mudança organizacional constrastantes, a representativista e a construtivista, que consideram a mudança organizacional possível por meio de aprendizagem coletiva, foram identificadas e comparadas em uma abordagem descritiva, reflexiva e metaparadigmática por Villardi (2004). Ali foram apontados os principais estudiosos da aprendizagem e da mudança organizacional que admitem esses processos e sua teorização como fenômenos inter-relacionados e socialmente construídos, numa dinâmica de tensão entre os distintos interesses. Assim como entre a racionalidade e a emocionalidade envolvidas na prática organizacional cotidiana. O objetivo desse estudo foi descrever, configurar e gerar um arcabouço conceitual para análise de microprocessos de mudança organizacional por meio de aprendizagem coletiva. Relatam-se, a seguir, as principais descobertas consideradas como um caminho promissor para compreender e teorizar reflexivamente a mudança e a aprendizagem subjacentes à prática dos empresários de EdC.

A busca de um arcabouço para o estudo da aprendizagem organizacional (AO) como um conceito unificado, com múltiplas perspectivas paradigmáticas, motivou Callahan e Schwandt (1999) a realizar um exame metateórico (epistemológico) das definições e das abordagens metodológicas usadas para investigar a aprendizagem organizacional. Objetivava preparar 
um caminho de estudo de AO num terreno comum. Assim desenvolveram um "arcabouço dinâmico de aprendizagem organizacional", com base na teoria geral de ação social de Talcott Parsons, para integrar as múltiplas perspectivas de 24 artigos apresentados na conferência "Aprendizagem Organizacional: movendo-se da teoria à pesquisa", realizada pela Academy of Management Review, em 1998.

Daí resultou um entendimento sobre a natureza não-linear do sistema de aprendizagem social; sobre a complexidade do ambiente que tem desafiado o modelo racional de gestão; e sobre uma mudança de cosmovisão na pesquisa que trouxe à tona conceitos como teoria do caos, dualidade, espiritualidade e sistemas auto-organizadores. Portanto, Callahan e Schwandt (1999) consideram AO "como um processo manifesto em padrões de ação e atributos de um sistema social ao invés de relações causais entre variáveis". Numa perspectiva sociológica, a localização dos processos de aprendizagem é imprecisa, pois se trata de sistemas de aprendizagem que ocorrem por meio de processos complexos e não-lineares permeando toda a organização (Callahan e Schwandt, 1999).

Tal entendimento favoreceria a difusão de práticas e aprendizagem em organizações com alta qualidade nas relações pessoais, sentido de unidade e comunhão entre seus membros, comunicação regular horizontal e vertical e redes de formação e educação para uma nova mentalidade, como é o caso das empresas de EdC (Linard, 2003; Kurtz, 2004; Sampaio, 2006).

Callaghan e Schwandt (1999) identificaram quatro subsistemas de aprendizagem nas organizações: de adaptação, de obtenção de metas, de integração e de manutenção de identidade. E os configuraram num arcabouço conceitual dinâmico de AO para explicar como os membros de organizações se empenham em ações sociais de aprendizagem. No conjunto dos 24 artigos analisados, os dois pesquisadores identificaram:

v duas perspectivas ontológicas em tensão - uma perspectiva estrutural sistêmica e uma interpretativista. A perspectiva estrutural-sistêmica enfoca a aquisição de informação e distribuição no ambiente organizacional. A perspectiva interpretativista enfoca a geração de significado sobre os eventos ambientais. Por exemplo, entre os pesquisadores de AO existem os desejosos de entender $\mathrm{AO}$ pelos comportamentos manifestos e os que acreditam que conceitos abstratos como AO nem sempre se manifestam em comportamentos concretos;

จ uma "comunidade acadêmica", onde se desenvolvem diversas perspectivas orientadas por diferentes paradigmas para estudar AO. Esta rubrica "comunidade acadêmica" apareceu como uma unidade de análise possível de ser 
examinada sob o "arcabouço dinâmico de AO" por eles proposto para capturar de forma sistêmica essas diferentes perspectivas dos estudos de AO.

Essa explicação parece proceder também para a prática dos empresários do projeto de EdC.

A popularidade da aprendizagem organizacional levou-a ao palco da teoria organizacional, onde Prange (2001) considera que a preocupação excessiva da área por fornecer estudos de "utilidade" para o gerente tem retardado a teorização sobre AO. E que isso reflete o predomínio de uma ontologia realista e uma epistemologia positivista acreditando que as teorias de AO proporcionam "ferramentas", não "lentes" para avançar o conhecimento da área (Prange, 2001:42).

Essa pesquisadora aprofundou-se na identificação das lógicas subjacentes e suas respectivas suposições epistemológicas e ontológicas; avaliou as condições de uma "boa" teoria em AO e identificou omissões nas abordagens existentes. Para tal avaliação utilizou três critérios que reconhece positivistas: consistência, ou seja, sua coerência lógica; incumbência descritiva/prescritiva, isto é, se os artigos pesquisados descreviam como alguma coisa é feita ou se exibiam traços prescritivos que explicavam como certo problema deve ser solucionado; "completude", ou seja, até que ponto as teorias de AO cobrem seis questões consideradas relevantes pelos pesquisadores de AO.

Com base em Burrel e Morgan (1979), Prange (2001) acredita, de modo crítico, que esses três critérios correspondem a uma posição modernista e positivista em pesquisa científica, que se apóia na premissa de que a sociedade tem uma existência real, concreta, fora da consciência. Ela também acredita que, pela prevalência dessa posição, a agenda de pesquisa em AO considera que: os problemas são prontamente identificáveis e há soluções ótimas para todos; aprender significa descobrir como as coisas funcionam, ou a maneira certa de fazer algo; o conhecimento é finito, passível de ser destacado em seus componentes e, identificável em sua incompletude ou deficiências; o mundo opera de acordo com princípios definidos.

Por ser essa visão positivista predominante nos estudos de $\mathrm{AO}$ criou-se a expectativa de que a teoria desenvolvida deva representar a realidade de maneira coerente, integrada e "útil". Esse critério de "utilidade" deve ser expandido para o de "praticabilidade" definida como a capacidade, além da utilidade, de uma teoria sensibilizar alguém sobre o que poderia ser, mais do que prognosticar o que será, pois as teorias servem como "lentes" para ajudar a ver as coisas de modo diferente e não são apenas "úteis", para remediar problemas aplicados (Prange, 2001). A teorização sobre EdC tiraria benefícios desse critério pelo seu declarado propósito transformador. 
Também examinando suposições implícitas, Huysman (2001:81) revisou a literatura sobre $\mathrm{AO}$ e identificou os estudos que respondiam a quatro das seis questões propostas por Prange naquele estudo publicado em 2001, caracterizando a literatura em AO. Concluiu que as respostas desenvolvidas apresentam tendenciosidades que têm levado os estudos em AO para direções únicas e seus pesquisadores a ignorarem outras visões possíveis sobre a aprendizagem organizacional.

As quatro tendências identificadas foram: tendência à ação individual, à adaptação ambiental, à aprendizagem planejada e à melhoria. A pesquisadora propôs formas de contrabalançá-las e assim abrir outras direções na pesquisa sobre AO.

Entre as recomendações feitas por Huysman (2001) para superar tendenciosidades nos estudos sobre aprendizagem, duas delas encontram algumas evidências nos estudos de Kurtz (2004) e Sampaio (2006), ou sejam, buscar escopo mais amplo para o processo de aprender e assumir uma perspectiva evolucionária onde a aprendizagem espontânea é significativa.

Ainda sobre o conhecimento produzido na área de aprendizagem organizacional, Hari e Crossan (2003) informam, em seu estudo bibliográfico do período 1990-2002, resultados obtidos por meio de estudos empíricos em AO e como contribuem com o conhecimento dessa área. Para tanto, pesquisaram todas as recentes publicações das revistas onde se divulgavam as pesquisas sobre AO mais citadas, levantando 707 textos e analisando diretamente 123 . Constataram que o desenvolvimento na área de AO apresenta: avanço para uma perspectiva influenciada pelas teorias de aprendizagem social; crescimento continuado exponencial em AO e, nas pesquisas empíricas que, até 2002, aparecem em igual proporção que a pesquisa teórica; necessidade de ampliar os níveis de pesquisa para incluir o interorganizacional, das redes e populações. Este, em particular, tem aplicações para o caso EdC quanto às relações entre o movimento dos focolares e as empresas do projeto, como delas entre si, numa rede de alianças formal existente no projeto para o aprendizado coletivo, objetivando atingir o ideário criado por Chiara Lubich em sua proposta de mudança.

Também há outras questões levantadas por esses autores que encontram interesse futuros estudos sobre aprendizagem em EdC, como o convívio entre a aprendizagem radical e a incremental, ou ainda a relação entre a formação da cultura da partilha e a aprendizagem coletiva de comportamentos e tarefas.

Nos estudos sobre aprendizagem, os diferentes pontos de vista sobre as propriedades essenciais da "organização" e do que se considera como processos de "aprendizagem" levaram a diferentes pensamentos e definições conceituais sobre o status ontológico e epistemológico do fenômeno de AO, assim como criaram um leque de abordagens para realizar pesquisa empírica. 
Assim, Hong (2003) identificou os respectivos pressupostos ontológicos e instâncias epistemológicas, de modo a clarificar os debates sobre a condução apropriada de pesquisa empírica em $\mathrm{AO}$ a partir das divergências sobre "quem aprende": se os indivíduos, os grupos, organizações ou as redes.

Para entender a orientação epistemológica do projeto EdC, parece pertinente considerar os estudos a partir do nível de grupo onde, de acordo com Hong (2003):

v estudam-se processos-chave de aprendizagem pelo engajamento coletivo tanto na preservação, ao compartilhar, quanto na atualização das práticas de trabalho diário, em resposta às mutáveis condições do ambiente de trabalho. Também se estudam dinâmicas interpessoais e intergrupais, analisando-as em suas estruturas, assim como a natureza emergente e situada (situated) da aprendizagem;

- os focos de pesquisa são: os diálogos, as atividades de trabalho "situadas" (in loco) e as dinâmicas relacionais e culturais entre os membros que aprendem na ação e em contextos específicos;

v há ainda deficiências conceituais relativas às "comunidades de prática" que compartilham práticas, identidades sociais e metas significativas. Também relativas à interação entre os membros, que parecem conduzir a processos de aprendizagem e determinar a forma de uma organização aprender;

v os domínios de estudo e entendimento resultante têm sido sobre as práticas sociais; sobre entender não tanto do que o indivíduo aprendeu cognitivamente, mas do quanto é capaz de realizar progressivamente por meio de contínua interação. E sobre o fato que esse processo acontece gradativamente, quando a prática de trabalho compartilhada é preservada, atualizada e mudada com outros membros das comunidades de aprendizagem pela legitimate peripheral participation (LPL) como definida por Lave e Wenger (1991).

\section{Considerações finais e recomendações para futura pesquisa}

O conhecimento desenvolvido no Brasil sobre as práticas de gestão das empresas de EdC sugere que esse projeto orienta-se por uma cosmovisão com predominância subjetivista, construtivista da realidade, que acredita no ser humano voluntarista (não-determinado), ator de suas convicções e capaz de transformação, de mudança da ordem econômica e social vigente. Estudos de orientação funcionalista esbarram nessas características epistêmicas, sem conseguir aprofundá-las, que são mais facilmente detectadas pelos de orientação interpretativista, usando métodos lingüísticos, ou pela crítica humanista. 
Os estudos sobre economia de comunhão mostram uma ampliação da consciência desses empresários para além da instrumentalidade e do individualismo nas ações organizacionais. Advém de uma nova mentalidade na gestão dos negócios, apesar de seguirem princípios espirituais milenares. Essa ampliação de consciência e a predominância da racionalidade substantiva nas empresas mais avançadas do projeto parecem ter sido desenvolvidas, de modo indutivo, pela práxis da espiritualidade cristã, que pode ter gerado processos concomitantes de aprender-mudar integrados por disposições estruturais do emocionar-refletir-agir desses empresários. O estudo de Machado (2006), ao examinar as possibilidades de uma teoria organizacional vir a explicar as práticas adotadas pelas empresas de economia de comunhão, concluiu que tal teoria só teria sucesso se fosse capaz de incorporar, em sua ótica de análise, os princípios da espiritualidade da unidade e do amor cristão. Esses princípios, interligados, são dotados de forte significado, são símbolos determinantes da prática transformadora seguida por esses empresários. Sua compreensão e incorporação na ação cotidiana definem a diferença entre sucesso e fracasso no aprendizado do que significa ser um empresário de EdC. Sem tal incorporação, a visão teórica perderia capacidade de explicação, o que nos parece evidente, quando se considera os pressupostos que orientam a pesquisa em administração.

A capacidade de os gestores mudarem, ao longo de suas vidas profissionais, com base em sua aprendizagem do que é ser um empresário de EdC, parece estar ligada a uma tendência filomática, nos termos de Antonacopoulou (2001:269), que merece ser também estudada. Os estudos de Kurtz (2004) e Sampaio (2006), que introduziram a questão da aprendizagem em EdC, como em outros estudos, não só sugerem essa disposição para o aprender, como também a disponibilidade das quatro organizações estudadas para desenvolver uma ambiência favorável à aprendizagem. A disposição parte das lideranças e contamina os empregados. Nessas organizações, como no movimento focolare, na realidade, tudo parece estar voltado para o desenvolvimento de um "homem novo", um novo empresário capaz de romper com os excessos do materialismo e do individualismo que impregnam as relações de troca. Estruturas, processos, comportamentos, tudo parece voltado para o aprender. Essa é, aliás, uma postura já percebida por Callahan e Schwandt (1999), como também por pedagogos (Mamede-Neves, 1999) que vêem a aprendizagem como parte indissolúvel do contexto organizacional.

Embora EdC não faça parte formal das relações contratuais, o ideário de Chiara Lubich, incorporado pelas lideranças, se estende ao discurso e à prática dos gerentes; está presente nos diálogos entre patrões e empregados. O sim- 
bolismo cristão atua aí como formador de cultura e responde por um clima amigável, solidário e cooperativo, acima da média de outras empresas. Ele possibilita a redução da indiferença, do isolamento entre indivíduos e evita as tradicionais formas de dominação e subordinação, inibindo também a mercantilização das relações pessoais.

Isso é o observado nas empresas mais avançadas no projeto, embora haja progressos diferenciados (Almeida e Leitão, 2003). Deve, todavia, ser observado que o projeto de EdC está se tornando ecumênico, ou mesmo adotado por agnostas de perfil profundamente ético. Não é mais um monopólio católico ou cristão.

A visão dominantemente comunitária que está construindo, ou reconstruindo, essas empresas, busca estabelecer uma nova relação do homem com o processo de produção, enfatizando a qualidade de vida nas relações de trabalho como na vida de cada membro da comunidade. Não se dissocia a vida pessoal da profissional. Toda essa ambiência favorece o aprender de comportamentos como de tarefas, como constataram Kurtz (2004) e Sampaio (2006), levando-os a concordar com a visão de que o aprender é fruto de uma complexa rede de relações. E onde a aceitação do outro como ser legítimo na convivência (amor-comportamento) surge como um grande facilitador da aprendizagem coletiva.

Em economia de comunhão e sua vocação para a aprendizagem, tudo sugere que um olhar socioconstrutivista crítico é privilegiado, pelo seu interesse em desvendar como as expressões humanas operam, ou para entender as práticas sociais e formas de vida e seus condicionantes, que o paradigma humanista radical enfatiza. Poderá, entre as epistemologias disponíveis, melhor detectar a força da linguagem cristã no trabalho e sua capacidade para construir a transformação empresarial e econômico-social pretendida pela idealizadora desse projeto.

Uma preocupação socioconstrutivista com a aprendizagem recomenda aprofundar o conhecimento da natureza dos grupos, isto é, as práticas sociais cotidianas de trabalho estudadas, entre outros, por Gherardi e Nicolini (2002) e Gherardi, Nicolini e Odella (1998) das "comunidades de prática", nos termos de Brown e Duguid (1991). E a epistemologia da aprendizagem "situada", ou situated learning, definida por Lave e Wenger (1991).

Por fim, propõe-se aqui, para continuação da pesquisa empírica, e futura formulação de uma teoria de EdC, investigar se a experiência de gestão praticada nas empresas do projeto de EdC confirma os indícios detectados de serem capazes de propiciar mudança transformadora, por meio de aprendizagem coletiva de uma mentalidade empresarial. Isso no nível micro, pois o nível macro dependerá da continuidade da expansão do projeto. Um estudo 
multiparadigmático, como os realizados por Schultz e Hatch (1996), que se utilize de uma perspectiva relacional, como proposta por Bradbury e Lichtenstein (2000), é um caminho possível nessa direção.

\section{Referências bibliográficas}

AKTOUF, O. A administração entre a tradição e a renovação. São Paulo: Atlas, 1996.

ALMEIDA, M. A. As empresas de economia de comunhão: possibilidade de valorização da racionalidade substantiva na organização econômica? 2002. Dissertação (Mestrado) - Departamento de Administração de Empresas, Pontifícia Universidade Católica, Rio de Janeiro.

; LEITÃO, S. P. Empresas de economia de comunhão e razão substantiva. RAP, v. 37, n. 6 , p. 1145-1170, nov./dez. 2003.

ALVESSON, M.; DEETZ, S. Teoria crítica e abordagens pós-modernas para estudos organizacionais. In: CLEGG, S.; HARDY, C.; NORD, W. (Orgs.). Handbook de estudos organizacionais. São Paulo: Atlas, 1999.

ANTONACOPOULOU, E. Desenvolvendo gerentes aprendizes dentro de organizações de aprendizagem: o caso de três grandes bancos varejistas. In: EASTERBY-SMITH, M.; BURGOYNE, J.; ARAÚJO, L. (Coords.). Aprendizagem organizacional e organização de aprendizagem. São Paulo: Atlas, 2001.

ASTLEY, W. G. Subjectivity, sophistry and symbolism in management science. Journal of Management Studies, v. 21, n. 3, p. 259-272, 1984.

Administrative science as socially constructed truth. Administrative Science Quarterly, n. 30, p. 497-513, 1985.

; VAN de VEN, A. Central perspectives and debates in organization theory. Administrative Science Quarterly, Worcester, n. 28, p. 245-273, 1983.

BRADBURY, H.; LICHTENSTEIN, B. M. B. Relationality in organizational research: exploring the space between. Organization Science, v. 11, n. 5, p. 551-564, Sept./Oct. 2000.

BROWN, J. S.; DUGUID, P. Organizational learning \& communities of practice: toward a unified view of working, learning and innovation. Organizational Science, v. 2, p. 40-57, 1991.

BRUNI, L. Comunhão e as novas palavras da economia. São Paulo: Cidade Nova, 2005.

BURREL, G.; MORGAN, G. Sociological paradigms and organizational analysis. London: Heinemann, 1979. 
CALLAHAN, J. J.; SCHWANDT, D. R. The academy as social system: a meta-framework for organizational learning. In: ORGANIZATIONAL LEARNING CONFERENCE, 3., 1999. Proceedings... Lancaster University, UK, p. 1-33, June 6-8. Disponível em: < http:// notes.lancs.ac.uk/pub/ol3.nsf/All? >.

CALLIARI, G. O projeto de economia de comunhão: acenos sobre a origem, o desenvolvimento e algumas repercussões. In: PINHEIRO, M. Baraúna (Coord.). Economia de comunhão e movimento econômico. Anais do Bureau Internacional da Economia e Trabalho. Vargem Grande Paulista: Cidade Nova, 2000.

CARVALHO, P. R. P. de. Organização de aprendizagem: uma exploração multidisciplinar sobre os obstáculos a sua implementação. 1998. Dissertação (Mestrado) — Departamento de Administração, Pontifícia Universidade Católica, Rio de Janeiro.

GHERARDI, S.; NICOLINI, D. Learning in a constellation of interconnected practices: cannon or dissonance? Journal of Management Studies, v. 39, n. 4, p. 419-436, 2002.

; ___ _ ODELLA, F. Toward a social understanding of how people learn in organizations: the notion of situated curriculum. Management Learning, v. 29, n. 3, p. 273297, 1998.

GIÓIA, D.; PITRE, E. Multiparadigms perspectives on theory building. Academy of Management Review, v. 15, n. 4, p. 603-625, 1990.

GONÇALVES, H. H. A. B. Q. A experiência dos pioneiros da economia de comunhão na liberdade no primeiro decênio (1991-2001) no Brasil: absurdo e graça da mudança de mentalidade do empresário. 2005. Tese (Doutorado) - Coordenação dos Programas de Pós-Graduação de Engenharia, Universidade Federal do Rio de Janeiro, Rio de Janeiro.

; LEITÃO, S. P. Empresas de economia de comunhão: o caso Femaq. RAP, v. 35, n. 6, p. 33-60, nov./dez. 2001.

HARI, B.; CROSSAN, M. From raising questions to providing answers: reviewing organizational learning research. In: ORGANIZATIONAL LEARNING AND KNOWLEDGE INTERNATIONAL CONFERENCE, 5., 2003, London. Proceedings... London, 2003.

HAWKINS, P. The spiritual dimension of the learning organization. Management Education and Development, v. 12, n. 2, p. 172-187, 1991.

HONG, J. F. L. Researching organizational learning: diversity of modes and methods. In: ORGANIZATIONAL LEARNING AND KNOWLEDGE INTERNATIONAL CONFERENCE, 5., 2003, London. Proceedings... London, 2003.

HUYSMAN, M. Contrabalançando tendenciosidades: uma revisão crítica da literatura sobre aprendizagem organizacional. In: EASTERBY-SMITH, M.; BURGOUYNE, J.; ARAÚJO, L. Aprendizagem organizacional e organização de aprendizagem. São Paulo: Atlas, 2001. 
KURTZ, R. G. M. Relacionamentos interpessoais e aprendizagem organizacional na economia de comunhão. 2005. Dissertação (Mestrado) - Departamento de Administração, Pontifícia Universidade Católica, Rio de Janeiro.

LAVE, J.; WENGER, E. Situated learning: legitimate peripheral participation. Cambridge: Cambridge University Press, 1991.

LIMA, M. A. B. Economia de comunhão x custos de transação: uma visão das organizações imbuídas da cultura da partilha. Read - Revista Eletrônica de Administração, ed. 12, v. 5, n. 4, nov./dez. 1999.

LINARD, K. T. Economy of communion: systemic factors in the rise of a new entrepreneurship. Systems Research and Behavioral Science, n. 20, p. 163-175, 2003.

LUBICH, C. A experiência da economia de comunhão a partir da espiritualidade da unidade. Uma proposta de agir econômico. In: BRUNI, L. (Org.). Economia de comunhão - uma cultura econômica de várias dimensões. São Paulo: Cidade Nova, 2002.

. Economia de comunhão, história e profecia. São Paulo: Cidade Nova, 2004.

MACHADO, A. C. M. Economia de comunhão: elementos para uma teoria organizacional. 2006. Tese (Doutorado) - Departamento de Engenharia Industrial, Pontifícia Universidade Católica, Rio de Janeiro.

MAMEDE-NEVES, M. A. C. Aprendendo aprendizagem. Rio de Janeiro: Departamento de Educação/PUC-Rio, 1999. CD-ROM.

MATURANA, H. Emoções e linguagem na educação e na política. Belo Horizonte: UFMG, 2001.

PINTO, M. C. S. A economia de comunhão sob o olhar da teoria dos stakeholders. 2004. Tese (Doutorado) - Departamento de Administração, Pontifícia Universidade Católica, Rio de Janeiro.

; LEITÃO, S. P. Economia de comunhão: empresas para um capitalismo transformado. Rio de Janeiro: FGV, 2006.

PRANGE, C. Aprendizagem organizacional: desesperadamente em busca de teorias? In: EASTERBY-SMITH, M.; BURGOUYNE, J.; ARAÚJO, L. Aprendizagem organizacional e organização de aprendizagem. São Paulo: Atlas, 2001.

RAMOS, A. G. A nova ciência das organizações. Rio de Janeiro: FGV, 1981.

ROMM, N. A trusting constructivist approach to systemic inquiry: exploring accountability. Systems Research and Behavioral Science Journal, n. 19, p. 455-467, 2002. 
SAMPAIO, M. A. L. Economia de comunhão e o conceito de organização de aprendizagem. 2006. Dissertação (Mestrado) — Departamento de Administração, Pontifícia Universidade Católica, Rio de Janeiro.

SCHULTZ, M.; HATCH, M. J. Living with multiple paradigms: the case of paradigm interplay in organizational cultural studies. Academy of Management Review, v. 21, n. 2, p. 529-557, 1996.

SCHWANDT, T. A. Three epistemological stances for qualitative inquiry. In: DEZIN, N.; LINCOLN, Y. (Eds.). Handbook of qualitative research. London: Sage, 1994.

SAMPAIO, Marcelo Alves Lopes; LEITÃO, Sergio Proença. Economia de comunhão e organizações de aprendizagem: compatibilidades conceituais. Revista de Administração Pública, v. 41, n. 3, p. 419-442, maio/jun. 2007.

SENGE, P. A quinta disciplina. São Paulo: Best-Seller, 1990.

SORGI, T. A cultura do dar. In: COSTA, R. et al. (Orgs.). Economia de comunhão. São Paulo: Cidade Nova, 1998.

TSOUKAS, $\mathrm{H}$. The word in the world: a critique of representationalism in management research. International Journal of Public Administration, v. 21, n. 5, p. 781-817, May 1998.

VILLARDI, B. Q. Os responsáveis por desenvolvimento humano nas organizações e as técnicas não tradicionais: a abordagem holística não se faz pela metade. 1997. Dissertação (Mestrado) — Departamento de Administração de Empresas, Pontifícia Universidade Católica, Rio de Janeiro.

. Um estudo reflexivo sobre microprocessos de aprendizagem e mudança coletiva docente. Para uma gestão sustentável do desenvolvimento de docentes em instituições de educação superior privada em administração e marketing. 2004. Tese (Doutorado) Departamento de Administração de Empresas, Pontifícia Universidade Católica, Rio de Janeiro.

WELLEN, H. A. O "novo" aos olhos do "velho": uma leitura da economia de comunhão a partir do pensamento de Marx. 2004. Dissertação (Mestrado) - Programa de Pós-Graduação em Administração, Universidade Federal do Rio Grande do Norte, Natal. 